\title{
Analysis of the energy consumption of a rotary harrow
}

\author{
Terenziano Raparelli, Alexandre Ivanov, Giuseppe Pepe, Gabriella Eula \\ Department of Mechanical and Aerospace Engineering, Politecnico di Torino, Torino, Italy
}

\begin{abstract}
This paper describes the development and study of a finite element numerical model (FEM) of a rotary harrow. A proper use of a rotary harrow depends on its geometry and its operating parameters, such as drag speed and angular speed. The aim of this work is to develop a rotary harrow model in the ANSYS environment in order to analyse and optimize its geometric parameters. After validating the model through a comparison with some experimental data, it was used to analyse the forces exchanged between the tines and the soil as a function of drag speed, angular speed and working depth. Different tine orientations and three different types of terrain were considered.
\end{abstract}

\section{Introduction}

The rotary harrow is a tool drawn by a tractor and is used to refine the soil before sowing or for weed control. It is driven by means of a power take-off (PTO) and is characterized by a series of vertical axis rotors, each rotating opposite to the next rotor, and equipped with vertical tines. The motion from the PTO is transmitted to the rotors by means of a reduction gear and a series of gear wheels. This study considered that the tillage process involves

Correspondence: Gabriella Eula, Department of Mechanical and Aerospace Engineering, Politecnico di Torino, Corso Duca degli Abruzzi 24, 10129 Torino, Italy.

E-mail: gabriella.eula@polito.it

Key words: Harrow tines and soil interaction; harrow tines during soil operation analysis; harrow tines and soil models; energy consumption in a rotary harrow; harrow tines functioning simulation.

Acknowledgements: this study was carried out as part of the PRIN project: (Progetti di ricerca di Rilevante Interesse Nazionale - bando 2015 'Ottimizzazione di macchine operatrici attraverso l'analisi del profilo di missione per un'agricoltura più efficiente' durata 2017-2020) (Research projects of significant national interest - notification 2015 'Optimization of operating machinery through analysis of the mission profile for more efficient agriculture' duration 2017-2020).

Received for publication: 21 October 2020.

Accepted for publication: 19 February 2021

(C) Copyright: the Author(s), 2021

Licensee PAGEPress, Italy

Journal of Agricultural Engineering 2021; LII:1132

doi:10.4081/jae.2021.1132

This article is distributed under the terms of the Creative Commons Attribution Noncommercial License (by-nc 4.0) which permits any noncommercial use, distribution, and reproduction in any medium, provided the original author(s) and source are credited. many factors that often modify the physical properties of the soil, such as texture, structure, bulk density, porosity, soil moisture (Cavazza, 1981; Terzaghi et al., 1996). Large amounts of energy are consumed during tillage operations because of the high draft forces required (Kushwaha et al., 1993). In fact, tillage is a procedure of soil breaking and loosening into small aggregates (Berntsen and Berre, 2002).

Soil preparation by means of a rotary harrow is a complex process and must meet various requirements. Three main problems can be highlighted, namely reliability of a harrow structure, energy efficiency of the process, quality of soil preparation. This study investigated the problem of energy consumption. As already mentioned, during the tillage phase, each rotor is subject to two movements: a horizontal dragging movement and a rotation around its own vertical axis. According to the speed, these movements create a complex movement of the rotary tines, mounted on the rotor (Raparelli et al., 2020). It is necessary to apply a certain power to overcome the resistance of the soil, subject to tillage, and to maintain the drag and angular speeds. This power depends both on the geometry of the harrow tines and on the tillage parameters, which are the two speeds, tillage depth and soil characteristics. For the calculation of this power, it is necessary to simulate the interaction between the tines and the soil. The studies conducted in this area are numerous and have led to the development of models that can be essentially classified into three categories: analytical models (Terzaghi, 1947; Swick and Perumpral, 1988; Kushwaha and Linke, 1996), empirical models (Luth and Wismer, 1971; Harrigan and Rotz, 1995) and numerical models (Yong and Hanna, 1977; Plouffe et al., 1999; Shinde et al., 2011; Chen et al., 2013).

The analytical models provide data related to the tool-soil interaction in a very fast way, but with high approximation. The empirical models provide data which are closer to physical reality, but require numerous and complex experimental measurements, therefore significant resources and time. The numerical models also provide very accurate results as long as one is able to define realistically the properties of the involved materials, the interface conditions and the constraint and load conditions. However, these models require experimental validation. Finite element numerical models (FEM) are very widespread. Their application to the study of harrow - soil interaction is however limited. A first approach to the study harrow - soil interaction was attempted by the same authors in Raparelli et al. (2019).

The approach to the study of the harrow-soil interaction using numerical modelling was considered by the same authors in (Raparelli et al., 2019), who mainly focused on the kinematics of the process. To obtain dynamic characteristics, it is necessary to use other computational schemes, the most important of which are numerical models based finite elements (FEM). This work is devoted to the creation of a numerical model that would lead to the determination of the dynamic characteristics of the rotary harrow, force and power consumption, as a function of its geometric dimensions and some operating parameters such as speed and depth of soil cultivation. Obviously, this model should be applied in practice with simultaneous monitoring of other parameters, since it only describes the reaction of the soil to the harrow tine, 
and does not provide detailed information about the state of the soil after passing the tine. This model may be used in the design and optimization of the rotary harrow along with other tools that would provide control over the quality of soil cultivation, strength, manufacturability, etc.

The use of this model together with tillage quality data under a particular regimen or a particular choice of the type of harrow tines could also make it possible to develop in the future some recommendations for reducing energy consumption during agricultural work.

\section{Materials and methods}

\section{Development of the rotary harrow tine finite element numerical model}

Generally, a rotary harrow has a series of rotors with two tines, which are operated by a series of gear wheels. These are moved by the tractor PTO with a cardan shaft drive interposed (Raparelli et al., 2018). Therefore, the rotor of the rotary harrow was modelled as two tines, positioned on a disk, as this is the actual geometry used by manufacturers. Figure 1 shows a view of the rotor model. This choice is justified by the standard geometry used in this implement and by the model used in the numerical simulations by the Authors (Raparelli et al., 2019, 2020). Considering that during the tillage operation the soil interacts only with the tines of the rotor, it is possible to simplify the shape of the rotor.

The shape of the tine and its position on the rotor has been modelled in the SOLIDWORKS environment, which allows to easily design the geometry. For example, in this case, it is possible to vary quite conveniently the orientation of the tines on the rotor. In the study, a rotor with a diameter of $0.25 \mathrm{~m}$ was chosen. The angle of the tine position on the rotor is a variable. Figure 2 shows a top view of a part of the rotor. In this case, the rotation speed is considered counter clockwise, and the $\alpha$ angle is the rotation angle of the tine with respect to the axis of the rotor. The $\alpha$ angle is positive in case of counter clockwise rotation and negative in case of clockwise rotation.

The tine shape was chosen from the models of the commercial tines and is shown in Figure 3 with its specific dimensions. This tine has high stiffness, therefore, it is possible to neglect the flexibility of the tines, while its length makes it possible to neglect the interference between the rotor body and the soil. The numerical model of the study was built in the ANSYS Explicit Dynamics module. The model must allow for the rotor movement to have a specific configuration of the tines in a block of soil. In order to avoid the excessive forces exerted in the beginning of the rotor movement, the rotor penetrates the soil block on one side with constant linear speed and angular speed and at a constant working depth. Figure 4 shows the initial step of the simulation. The linear trajectory of the rotor drag movement imposed is equal to about two of its diameters, which makes it possible to stabilize its movement. During its motion both the forces acting on the rotor in the direction of its linear movement and the total work done were recorded.

This makes it possible to determine its total power consumption $P$ tot, and the power required to move the harrow $P$ mov. Obviously, the power derived from the PTO for the rotation of the harrow $P$ rot is equal to the difference between $P$ tot and $P$ mov.

During the development of a FEM model, one of the main problems to address is the choice of a soil material model. Unfortunately, this choice cannot be made on the basis of the chemical properties and composition of the soil, for example, using the triangular diagram of soils (Giordano, 1999). The percentage of substances in the soil does not directly determine the

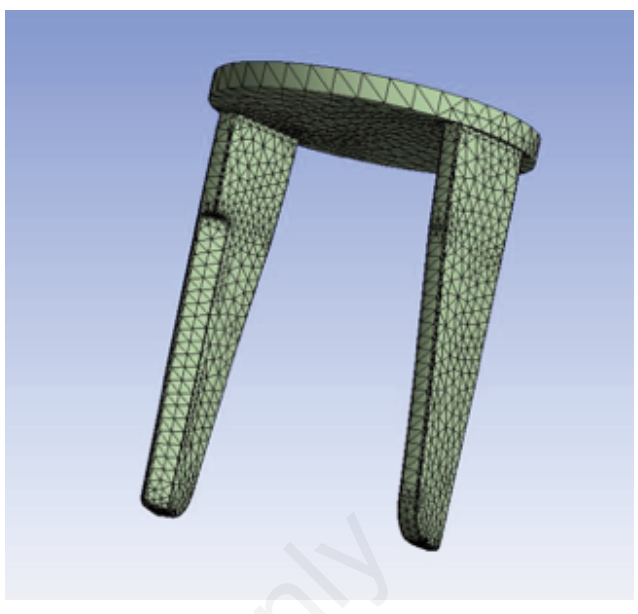

Figure 1. Model of a rotor.

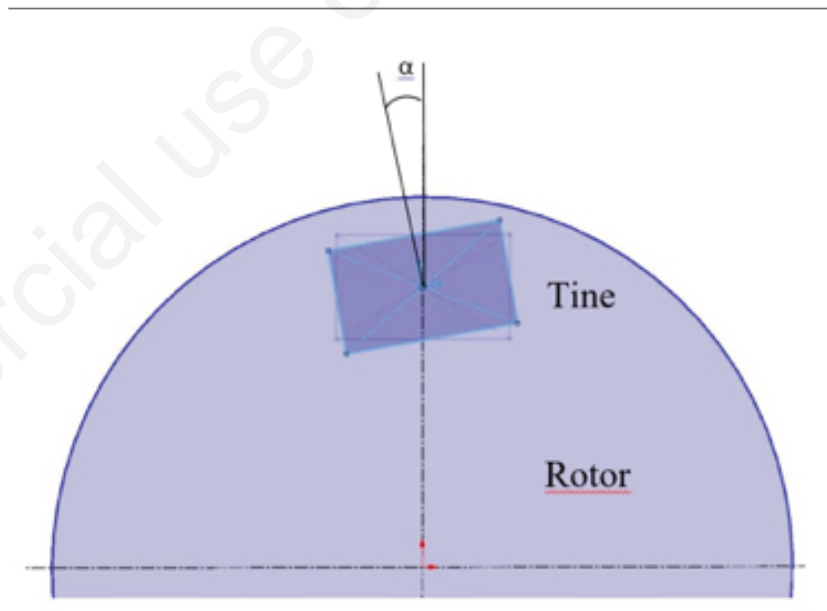

Figure 2. Position of the tine on the rotor.
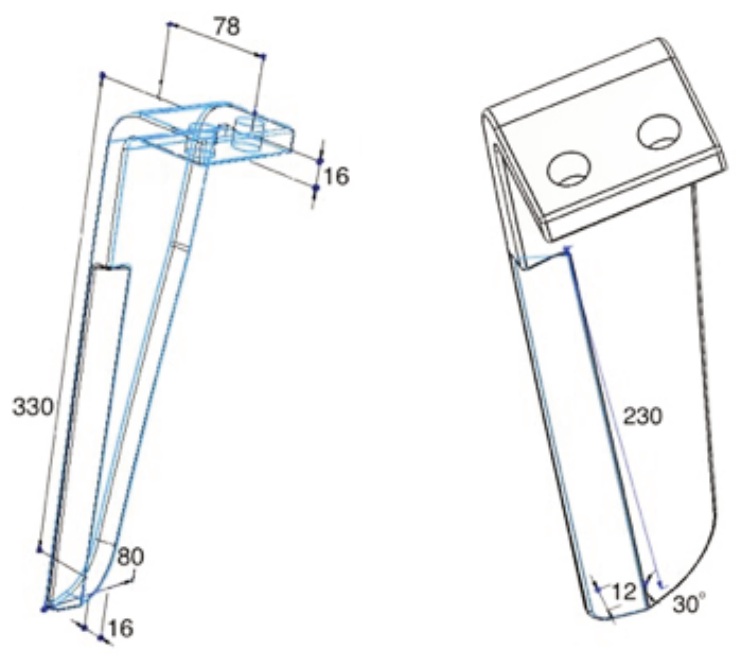

Figure 3. Tine shape with dimensions. 
characteristics of the model material, and different soil models may be required for different tasks. One of the recommended models is the MO Granular model (Laine and Sandvik, 2001). This model is an extension of Drucker-Prager model that takes into account the effects associated with granular materials such as powders, soil and sand. It combines the compaction EOS model with Moxnes and Ødegardstuen granular strength model. In addition to pressure hardening, the model also represents density hardening and variations in the shear modulus with density. The yield stress is made up of two components: one dependent on the density and one dependent on the pressure. The unload/reload slope is defined by the shear modulus which is function of the zero-pressure density of the material. The yield stress is defined by a yield stress pressure curve and a yield stress - density curve and the shear modulus is defined by a shear modulus - density curve.

Three types of standard materials from the ANSYS material library were used as soils: Silty Sand, Sandy Clay and Sand. Simulations of the rotor movement were carried out. Sand was chosen as a model soil material, because its characteristics are well studied and it is the limiting case for the triangular diagram of soils, when the content of other components is zero (Giordano, 1999). The working parameters of the harrow were selected based on their characteristic values. The maximum tillage depth for the selected tine geometry (Figure 3 ) does not exceed $23 \mathrm{~cm}$, and should actually be less. Rotary harrow processing at depths of less than $10 \mathrm{~cm}$ seems impractical. Therefore, three working depths were chosen: 10,15 and $20 \mathrm{~cm}$. The drag speed of the rotor and the angular speed of the rotor were selected based on average values,
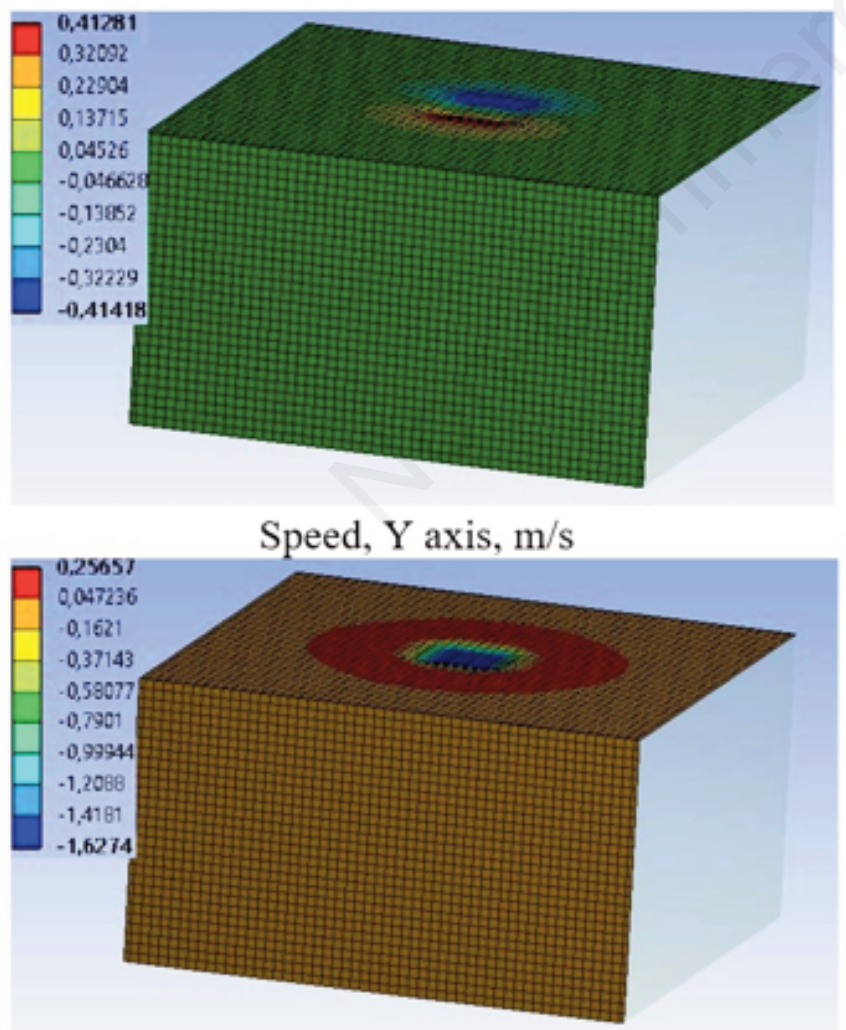

Speed, $\mathrm{Z}$ axis, $\mathrm{m} / \mathrm{s}$ tractor speed about $4.3 \mathrm{~km} / \mathrm{h}$, PTO angular speed $540 \mathrm{rpm}$, gear ratio 0.6. Therefore, drag speed of the rotor and the angular speed of the rotor were set at $1.2 \mathrm{~m} / \mathrm{s}$ and $35 \mathrm{rad} / \mathrm{s}$, respectively.

Simulations of the rotor movement were carried out by varying the angle of the knife $\alpha$. The angle $\alpha$, according to Figure 2, was varied from $+10^{\circ}$ (with the most 'closed' tines), to $-10^{\circ}$ (with the most 'open' tines).

\section{Validation of the finite element numerical model of the soil}

To verify the applicability of the standard soil models, a series of preliminary numerical simulations dedicated to the study of the soil behaviour were performed. In the simulation of the interaction

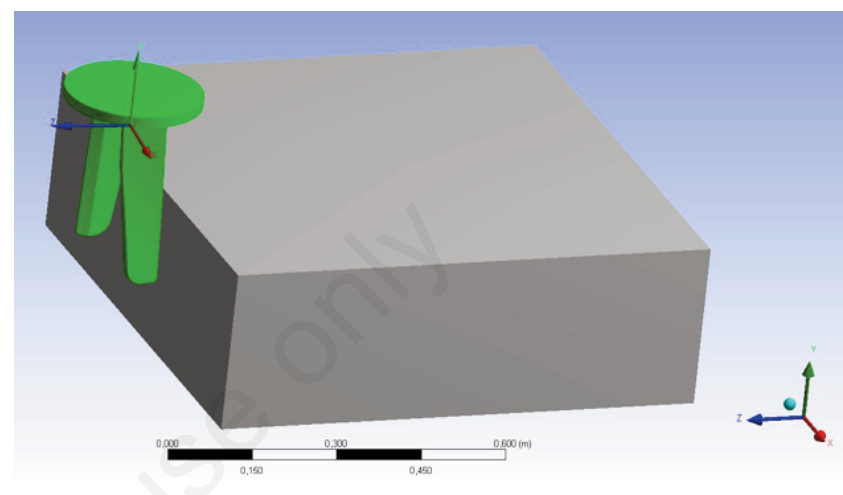

Figure 4. Initial geometry of the model.

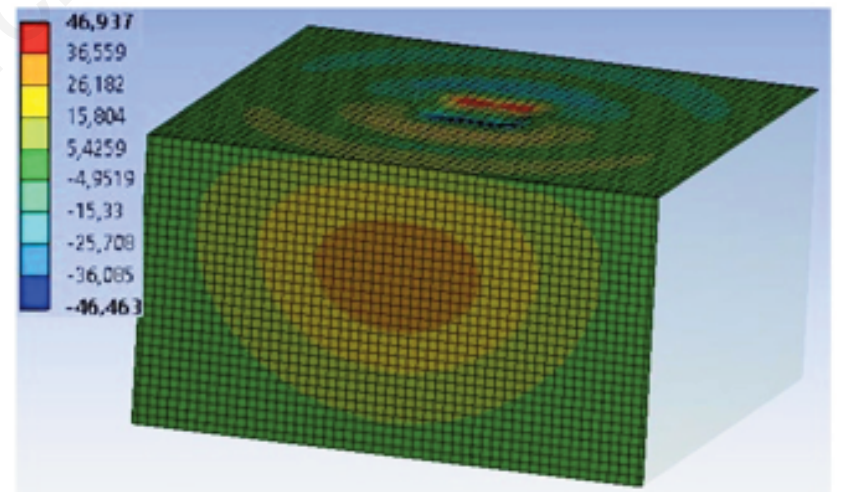

Acceleration, $\mathrm{Y}$ axis, $\mathrm{m} / \mathrm{s}^{2}$

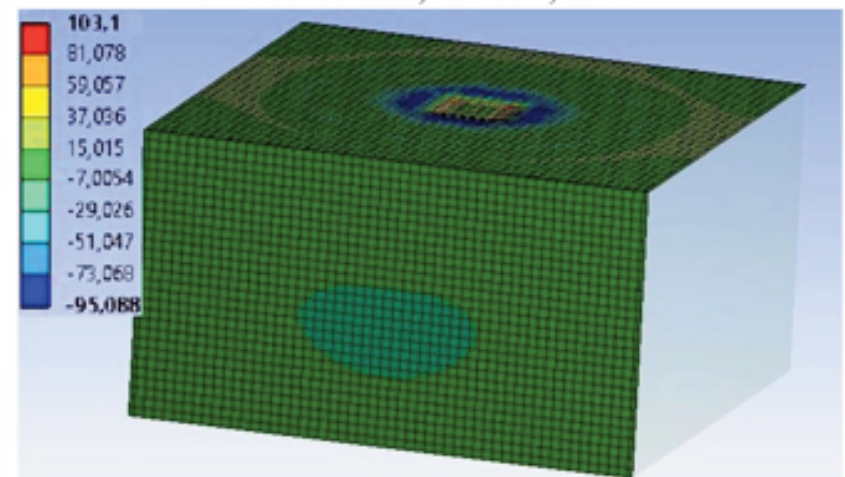

Acceleration, $\mathrm{Z}$ axis, $\mathrm{m} / \mathrm{s}^{2}$

Figure 5. Speed and acceleration. Silty Sand, $t=3 \mathrm{~ms}$. 


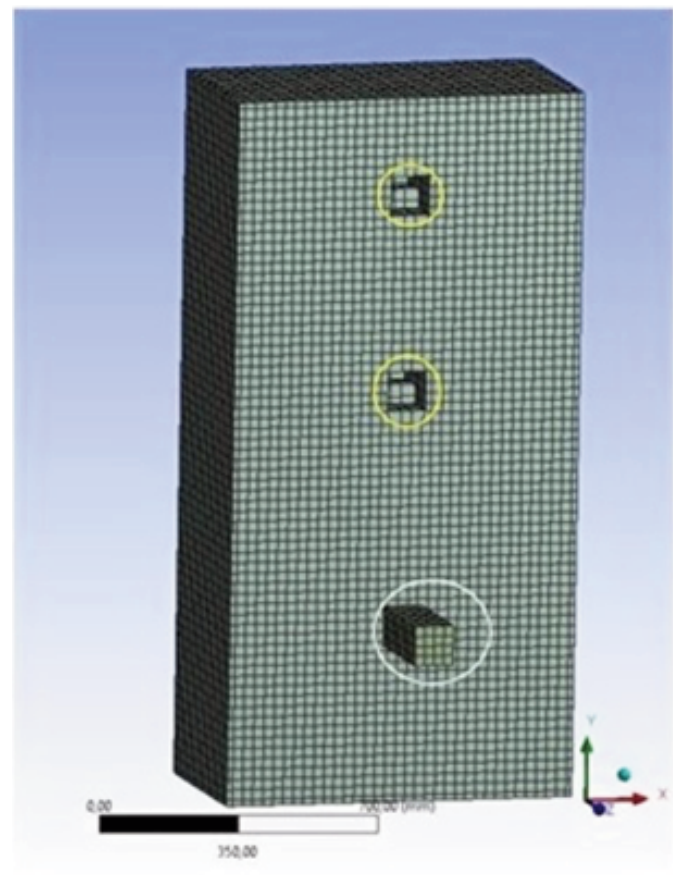

(A)

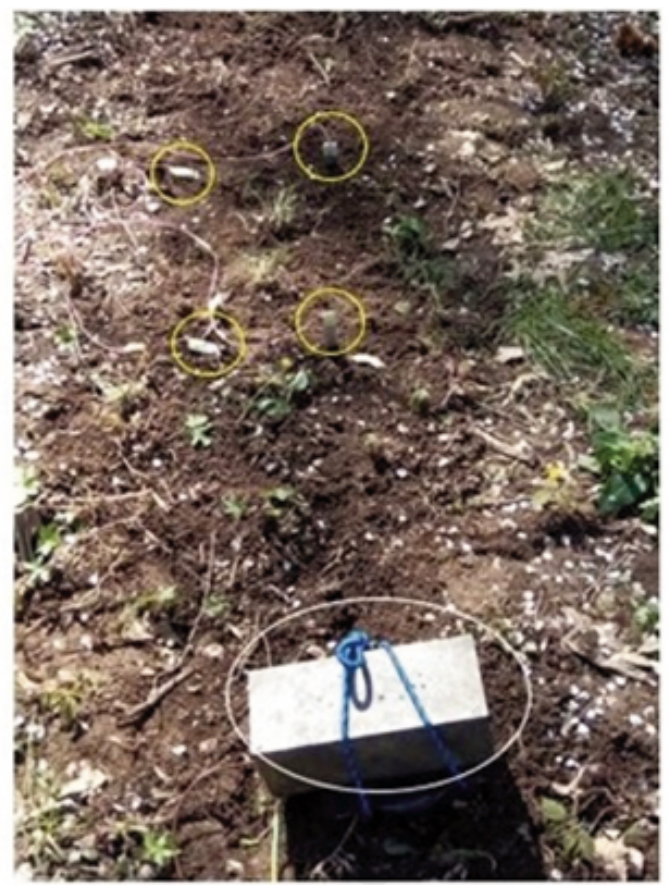

(B)

Figure 6. Model geometry for the study of the soil behaviour. A) ANSYS model; B) field test. The yellow circles indicate the location of the sensors, while the white circles indicate the location of the body.

between the tines of the harrow and the soil, the rotor can be assumed as a rigid body, because its stiffness is greater than that of the soil.

Since the standard soil models from ANSYS were supposed to be used in the construction of the harrow model, the validity of their application for the conditions of the developed model was initially checked.

For this purpose, a simplified ANSYS model of soil behaviour was chosen so that its parameters could be easily measured. In the model, the mass falls on the block (that simulates the soil) at a speed similar to that of the tillage operation, and the velocities and the accelerations of the soil were measured at a certain distance from the point of fall. The model was made with the ANSYS Explicit Dynamics. Figure 5 shows the results for speed and acceleration along the direction of propagation of the impact ( $\mathrm{Y}$ axis) and perpendicular to the direction of propagation ( $\mathrm{Z}$ axis), 3 milliseconds after the impact. As can be seen, the speed values are very low, while the acceleration in the deep zone of the block is remarkable and could be easily measured. The geometry chosen for the tests is shown in Figure 6. To better highlight the measurement point, small 'wells' were used.

The calculations have shown that the absolute acceleration depends slightly on the impact parameters, i.e. body speed and mass, but the characteristics do not change. Figure 7 presents some graphs with the calculation of the normalized acceleration $a$ for the three soil models, Sand (S), Silty Sand (Ss) and Sandy Clay (Sc).

The experimental test was carried out according to the scheme in Figure 6B. Two accelerometers were placed along a straight line including the place of impact for a more accurate detection of the signal propagation time. The signal transit time was defined as the difference between the times recorded by the two sensors. This also made it possible to eliminate any delays in the signal from the accelerometers. In experiments, two accelerometers were generally used to measure accelerations along the $\mathrm{Y}$ and $\mathrm{Z}$ axes. Figure 8 presents two experimental results for Sand and Silty soil.

The comparison between Figures 7 and 8 highlights a similar behaviour in both the theoretical model for Silty Sand and the result of the experimental tests. However, this similarity is less evident in the Sand model. This discrepancy can be caused by the moisture content of the sand.

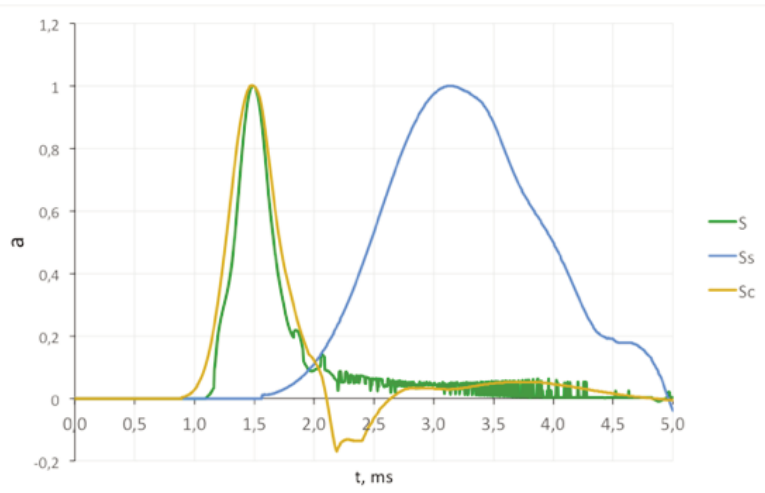

Figure 7. Acceleration for Sand (S), Silty Sand (Ss) and Sandy Clay (Sc). 


\section{Results of the tine-soil interaction simulation}

After the preliminary analyses concerning the impact propagation, simulations of the soil tillage interaction were carried out. The variable parameters were depth $h$ and angle $\alpha$ of the tine positioning. Figures 9 and 10 show some results of the calculations for Silty Sand (Ss). The working depth was $15 \mathrm{~cm}$ and angle $\alpha$ was $0^{\circ}$. Figure 9 shows the graph of the force $\mathrm{F}$ exerted on the rotor in the direction of its displacement, as a function of the time. Figure 10 shows the graph of the system energy as a function of the time. The part of the power corresponding to the linear displacement was calculated as the average force multiplied by the drag speed, which was equal to $1.2 \mathrm{~m} / \mathrm{s}$.

In the first series of tests, simulations of the rotor movement were made at the three previously defined depths with an $\alpha$ angle value equal to $0^{\circ}$ by varying the material of the soil block. Figure 11 shows the results for the average power calculated for the three types of soil: Sand (S), Silty Sand (Ss) and Sandy Clay (Sc). In the graphs, $P$ mov. $(\mathrm{kW})$ is the average power required to move the rotor and $P$ tot. $(\mathrm{kW})$ is the total average power. The total average power is the sum of the power required for the linear movement of the rotor and the power for its rotation. The power was calculated for the last two turns of rotor to eliminate the influence of the tine impact on the soil block which takes place in the first moment of movement. As can be seen, the powers for Silty Sand and Sandy Clay do not differ much, and, as expected, the power required when processing Sand is much lower. The results of numerical simulations have shown that the total power required could be expressed according to the following formula:

$P_{t o t}=P_{0}\left(A H^{2}+B H+C\right)$

where: $P_{0}$ - power in $\mathrm{kW}$ at a working depth of $1 \mathrm{dm}$; $\mathrm{H}$ - working depth in dm; A, B and C are constant. For Silty Sand and Sandy

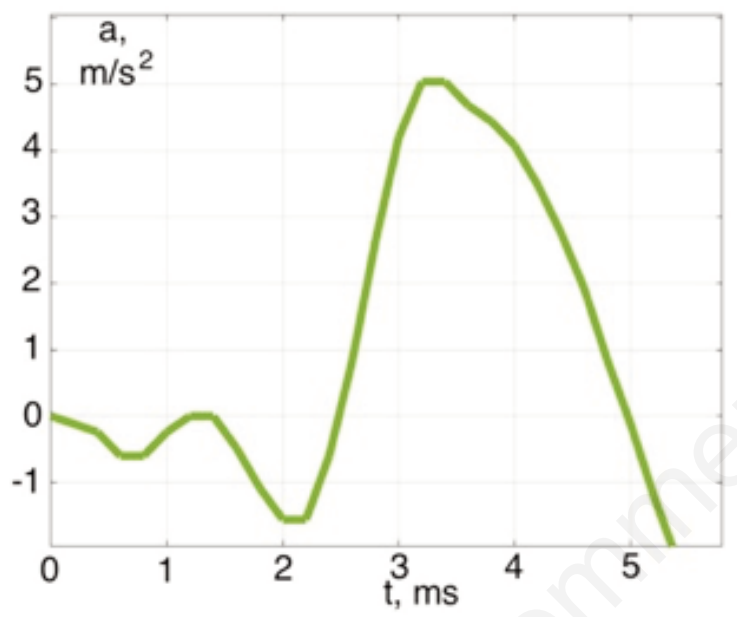

(A)

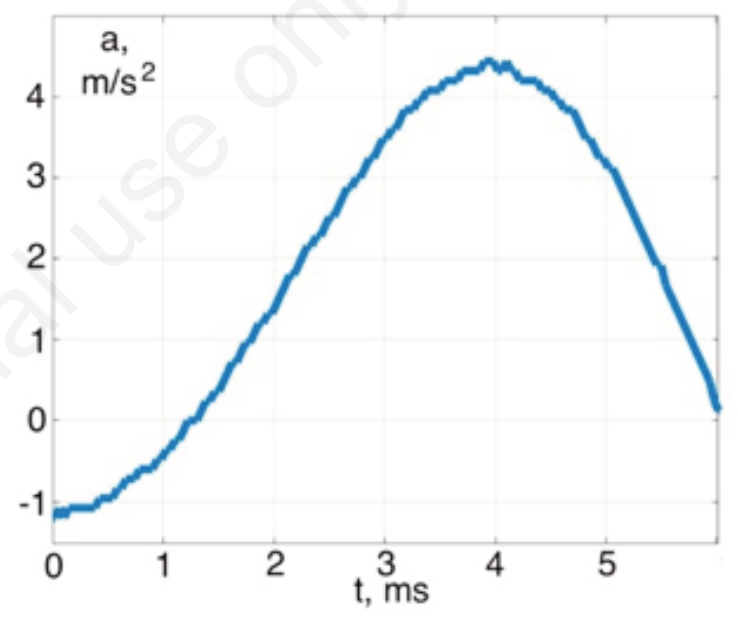

(B)

Figure 8. Experimental results from measurement of acceleration a for Sand (A) and Silty Soil (B).

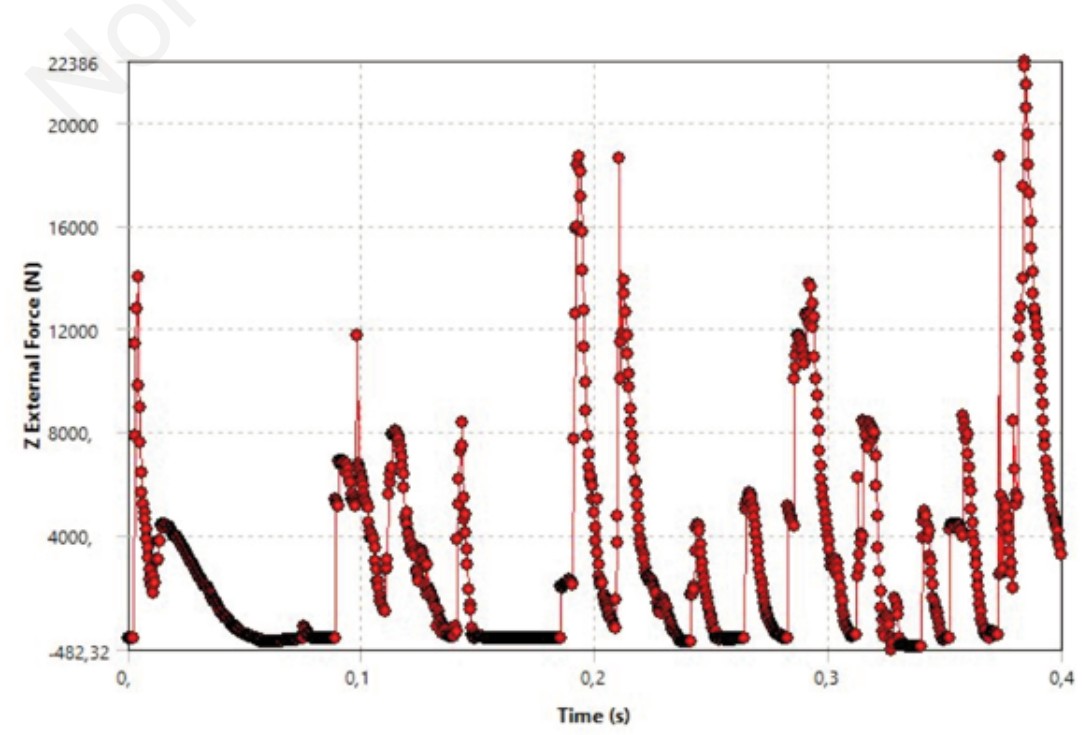

Figure 9. Force along the direction of displacement. 
Clay the same values of the coefficients can be used. The values of the coefficients A, B and C are shown in Table 1.

In the second series of tests, the angles of the orientation of the tines on the rotor were changed, according to Figure 2. The modelling results are presented in Figure 12, for the soil model Silty Sand (Ss) above and below for the Sand (S). Like before, the reported powers are the average powers relative to the last two rotor turns without the influence of the first impact. Figure 12 shows that a slight increase in angle $\alpha$ decreases the power required, both for Sand and Silty Sand. The 'closing' of tines at 510 degrees made it possible to decrease the necessary power, according to the depth and type of soil, up to $10 \%$. To evaluate the dynamic behaviour of the power over time the trajectory of rotor was divided in four parts. Each part corresponds to the average power during a half turn, therefore, there are four values of the average powers for the two turns (for the rotor movement and the total movement). Figures 13 and 14 show the results for the tests and refer respectively to Silty Sand (Ss) and Sand (S). In both cases, there are soil accumulations, which cause an increase in power. However, for Sand the results refer to the first half turn, while for Silty Sand they refer to the last. In any case, the use of 'closed' tines, mounted at a larger angle, presents a more uniform power recall.

\section{Conclusions}

A FEM model has been built to describe the power characteristics of the harrow rotor. This model contains a rotor with two tines, which rotates at a constant angular velocity and moves with a constant linear velocity. In this case, the rotor tines interact with the soil material. During the movement of the rotor, the applied forces were fixed in order to determine the necessary powers for its rotation and movement. This model makes it possible to investigate the influence of speed, tillage depth, shape and position of tines on power consumption.

The same powers were applied to the ground in which the rotor tines rotated, thus changing its state. The description of soil changes is a very important independent task, but this goal was not pursued in this work.

When constructing the model for soil characterization, three standard materials from the ANSYS materials library, Silty Sand, Sandy Clay and Sand soil models were used, all three types were
MO granular. Before investigating the characteristics of the model, the possibility of using this model of material was preliminarily verified. The construction of a FEM model of the mass impact propagation on the soil at a speed similar to the tillage speed, and the measurement of the resulting accelerations were compared with experimental results.

The theoretical results for the Silty Sand soil model were similar to the experimental ones, but the Sand soil model required the adjustment of some parameters. The resulting data showed, on the one hand, the possibility for further use of the MO granular model in the developed model, and, on the other hand, revealed the need for accurate measurements of the characteristics of the cultivated soil.

For a chosen rotor geometry, the values of the required power for the Silty Sand, Sandy Clay and Sand soil models for three dif-

Table 1. Coefficients for the calculation of the power required for tillage.

\begin{tabular}{lccc} 
& A $\left(\mathrm{kW} / \mathrm{dm}^{2}\right)$ & B $(\mathrm{kW} / \mathrm{dm})$ & $\mathrm{C}(\mathrm{kW})$ \\
Silty Sand - Sandy Clay & 1.45 & -2.6 & 2.15 \\
Sand & 1.2 & -2.6 & 2.4 \\
\hline
\end{tabular}

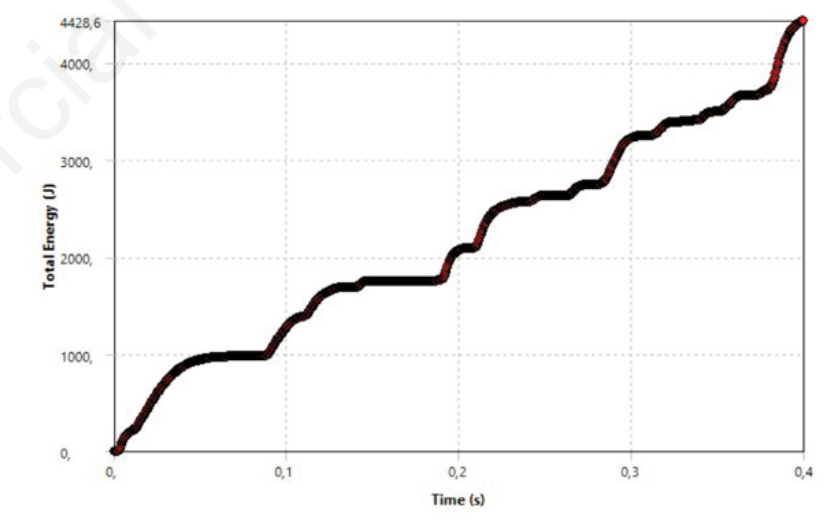

Figure 10. Energy for the work done.

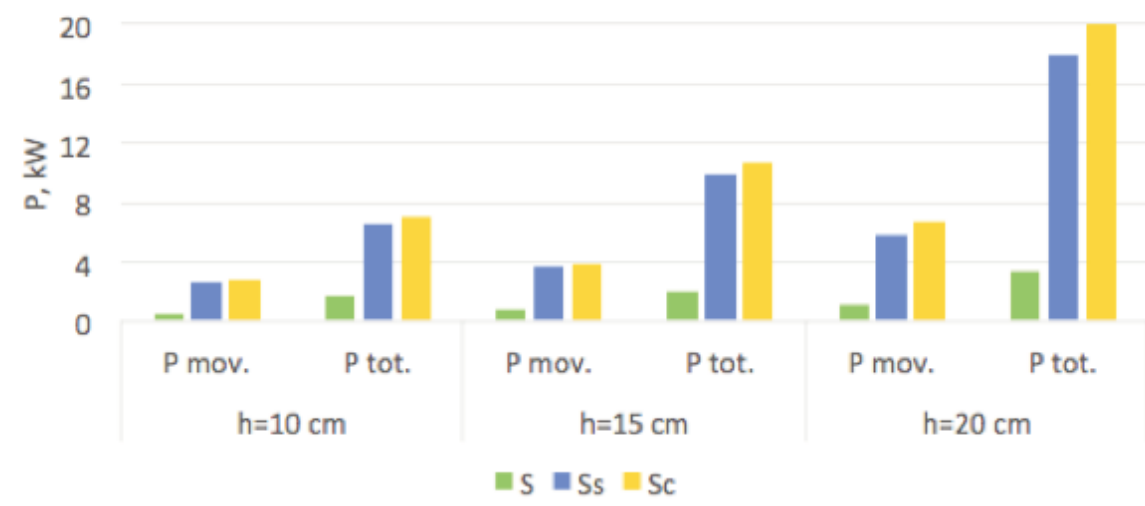

Figure 11. The average power for the three types of soil: Sand (S), Silty Sand (Ss) and Sandy Clay (Sc). 

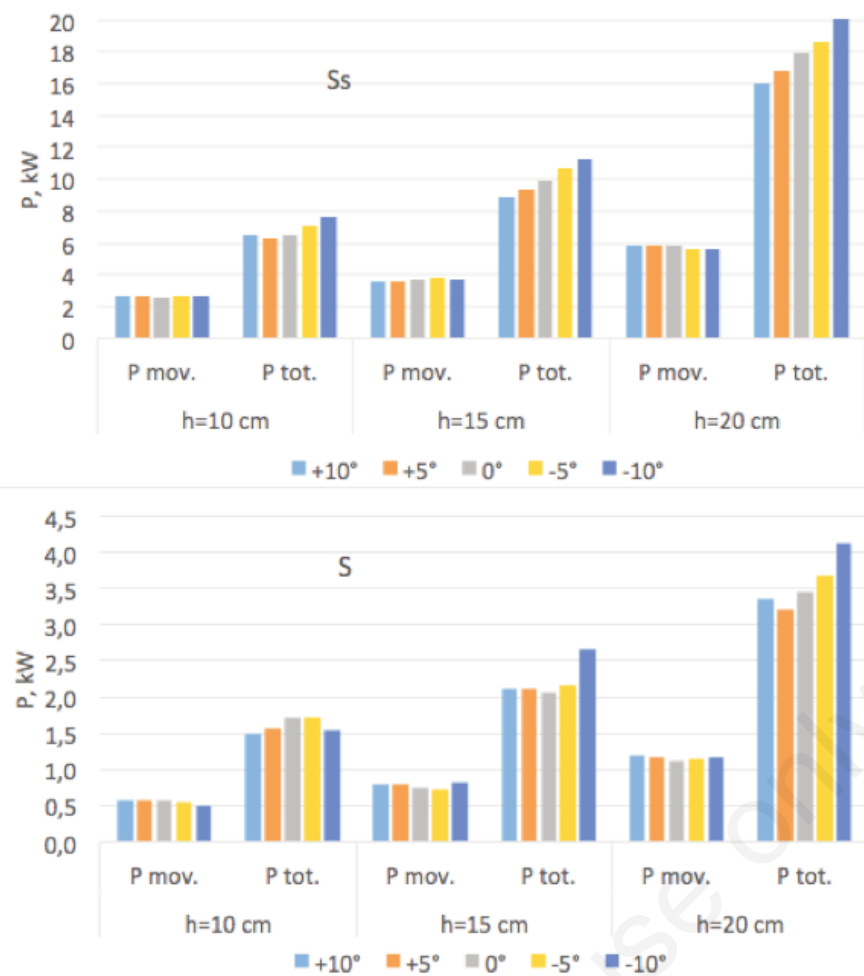

Figure 12. The average powers as a function of the tine angle for Silty Sand (Ss) and Sand (S) models.

\section{$\mathrm{Ss}, \mathrm{h}=10 \mathrm{~cm}$}

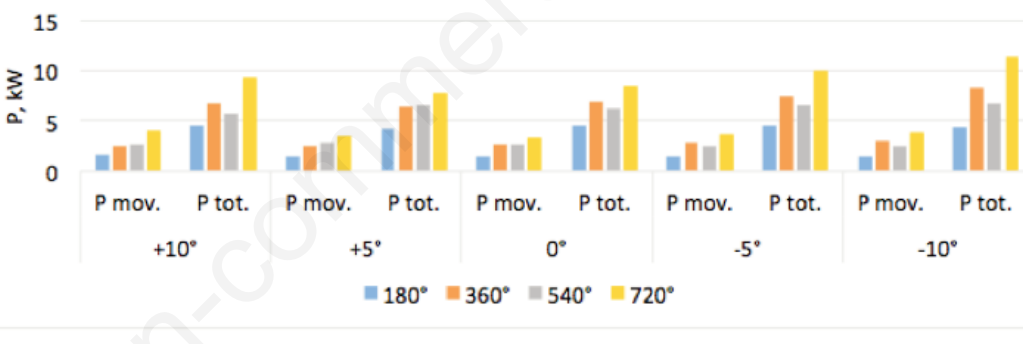

Ss, $\mathrm{h}=15 \mathrm{~cm}$

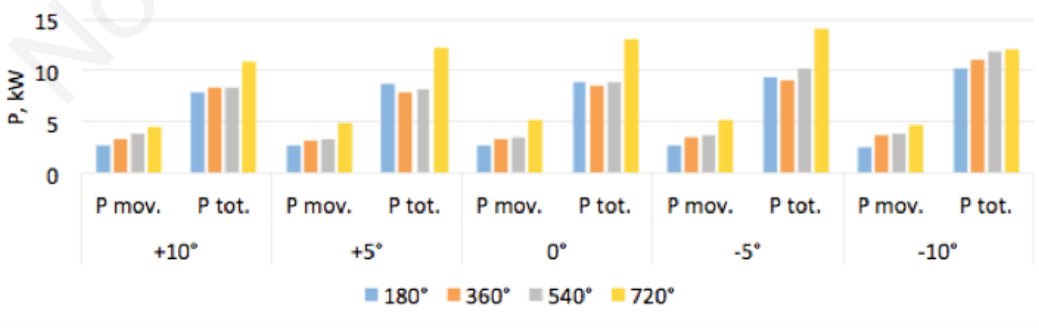

$\mathrm{Ss}, \mathrm{h}=\mathbf{2 0} \mathrm{cm}$

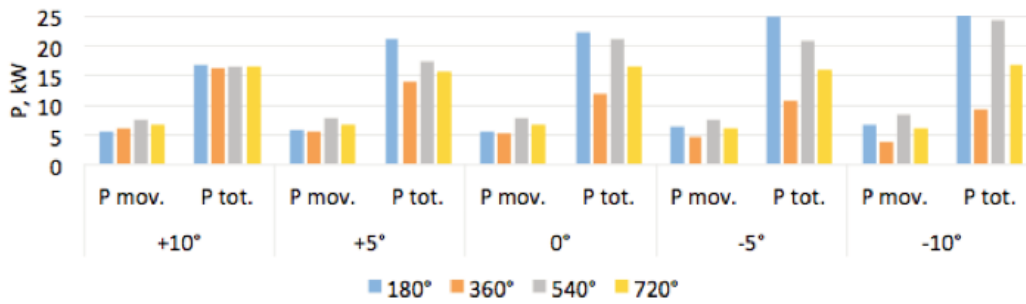

Figure 13. The average powers as a function of the tine angle for the Silty Sand model (Ss). 


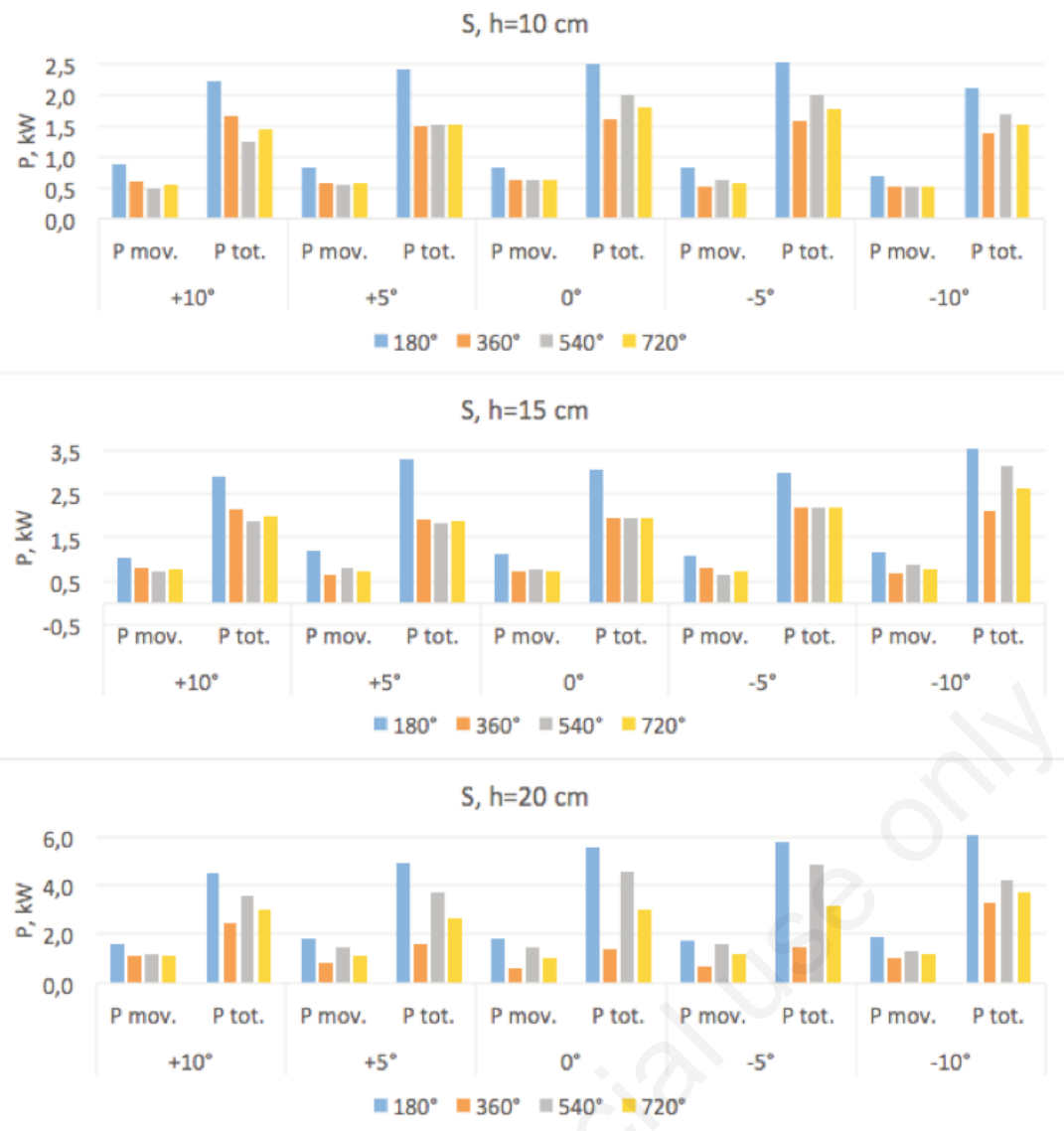

Figure 14. The average powers as a function of the tine angle for the Sand soil model (S).

ferent working depths were examined and compared.

Based on the numerical modelling results, a generalized formula was obtained for the power consumed by the rotary harrow for three applied soil models. The formula for the required power with variation of the working depth for Sand and for Silty Sand and Sandy Clay had slightly different coefficients.

Numerical tests with different positioning angles and different treatment depths were carried out for two soil models, Silty Sand and Sand, because their behaviour in the developed model was significantly different. These tests showed that a slight increase in the angle decreases the required power and makes it uniform and also decreases energy consumption for both models.

The practical use of this model can consist in a series of fullscale tests both to verify the model as a whole and to determine the characteristics of the soils used for the models. In this case, it provides an additional tool for developers of new technology. The obtained analytical dependence can be applied to a wide range of agricultural soils and be used by farmers to optimize costs, for example, selecting the appropriate tractor capacity.

\section{References}

Berntsen R., Berre B. 2002. Soil fragmentation and the efficiency of tillage implements. Soil Till. Res. 64:137-47.

Cavazza L. 1981. Fisica del terreno agrario. UTET, Torino, Italy.
Chen Y., Munkholm L.J., Nyord T. 2013. A discrete element model for soil-sweep interaction in three different soils. Soil Till. Res. 126:34-41.

Giordano A. 1999. Pedologia. Edizioni UTET, Torino, Italy.

Harrigan T.M., Rotz C.A. 1995. Draft relationships for tillage and seeding equipment. Appl. Engine. Agricult. 11:773-83.

Kushwaha R.L., Chi L., Shen J. 1993 Analytical and numerical models for predicting soil forces on narrow tillage tools - a review. Canad. Agricult. Engine. 35:183-93.

Kushwaha R.L., Linke C. 1996. Draft-speed relationship of simple tillage tools at high operating speeds. Soil Till. Res. 39:61-73.

Laine L., Sandvik A. 2001. Derivation of mechanical properties for sand. pp 361-368 in Proc. 4th Asia-Pacific Conference on Shock and Impact Loads on Structures, CI-Premier PTE LTD, Singapore.

Luth H.J., Wismer R.D. 1971. Performance of plane soil cutting blades in sand. Trans. ASAE. 15:0211-6.

Plouffe C., Lague C., Tessier S., Richard M.J., Mclaughlin N.B. 1999. Moldboard plow performance in a clay soil: simulation and experiment. Trans. ASAE 42:1531-9.

Raparelli T., Eula G., Ivanov A., Pepe G. 2018. Analisi della catena cinematica per la trasmissione del moto dal trattore a un erpice rotativo. Organi di Trasmissione 10:X-XIV.

Raparelli T., Eula G., Ivanov A., Pepe G., Ricauda Aimonino D. 2019. Preliminary analysis of interaction among gears, tines and soil in a rotary harrow. Int. J. Mechan. Control. 20:81-91. 
Raparelli T., Pepe G., Ivanov A., Eula G. 2020. Kinematic analysis of rotary harrows. J. Agricult. Engine. 51:976, 9-14.

Shinde G.U., Potekar J.M., Shinde R.V., Kajale S.R. 2011. Design analysis of rotary tillage tool components by CAD-tool: rotavator. 2011 International Conference on Environmental and Agriculture Engineering IPCBEE, vol.15, IACSIT Press, Singapore.

Swick W.C., Perumpral J.V. 1988. A model for predicting soil-tool interaction. J. Terramechan. 25:43-56.

Terzaghi K. 1947. Theoretical soil mechanics. 4th ed. Chapman and Hall-Wiley, London and New York, UK and USA.

Terzaghi K., Peck R.B., Mesri G. 1996. Soil mechanics in engineering practice. 3rd Edition. John Wiley \& Sons, New York, NY, USA.

Yong R.N., Hanna A.W. 1977. Finite element analysis of plane soil cutting. J. Terramechan. 14:103-25. 